should be spent in the psychiatry of old age. The 1987 Handbook uses instead the phrase "a recommended period of four years and a minimum of three" as a criterion for appointment to a consultant post for all branches of psychiatry other than in the psychiatry of old age, general psychiatry with a special interest, and in the special hospitals. In the psychiatry of old age the element of psychogeriatric experience is now to be "usually eighteen months."

I understand that this is not just a paper change, for I believe that the College has instructed its representatives on Advisory Appointments Committees to adhere to these guidelines rigorously. That the College is doing so may be because of its wish to be consistent with its arguments to the Joint Planning Advisory Committee on senior registrar numbers, which resulted in an increase in manpower approval. However, it will be some little time before these new senior registrar posts have any influence on the number of applicants for consultancies. Therefore, by diminishing the supply of suitable applicants, through applying these new criteria before these new senior registrar postholders have completed their four years of training, the College is inducing a dearth of "suitably qualified applicants" for consultant posts throughout the country.

A further interesting aspect of this situation is how little this change has been discussed outside of Belgrave Square. Indeed, many of my colleagues would seem to have been unaware that the JCHPT had made such a change. I would be interested to hear through your correspondence columns whether this experience is widespread, and what are the views of your readers on the appropriateness of the College moving the goal-posts in this way.

Royal Children's Hospital

J. W. T. LOVETT

Alder Hey, Liverpool LI2 $2 A P$

\section{Higher media profile for the College}

DeAR SiRS

I am writing as a consultant psychiatrist who is a current BMA Divisional Secretary (West Glamorgan) and who was also a member of this College's first Collegiate Trainees' Committee.

In the course of my work with the BMA I have become conscious of the admirable efficacy of the Association in day to day political matters due in no small part to the efforts of Mrs Pamela Taylor and her highly professional staff in the BMA Public Affairs Division. Thanks to this unit the BMA is able to plan its responses in the media to current issues, especially perhaps Government policy, and to deliver a polished performance which helps the Association maintain its key role in influencing public opinion on health matters.
While recognising the differences between the functions of a Royal College and a professional association which is also a trade union, I have been concerned that there have perhaps been times when our College does not seem to have reached this standard of media professionalism and rapidity of response. The public image of psychiatry is currently less satisfactory than many of us would wish and I am sure that many are also conscious that some of the voluntary bodies and pressure groups have at times been more effective in influencing mass public opinion than our own profession. Examples of this include some of the consequences of the 1983 Mental Health Act and also the worrying backlash against all biological treatments following the, quite proper, concern over benzodiazepine prescribing.

Currently of course medical services in this country, including our own speciality, are faced with a most serious threat in the form of the Government's White Paper-Working for Patients - which seems to put in jeopardy the very continued existence of the NHS in its present form. I am sure the Presidents of the Royal Colleges did not realise what they were unleashing when they petitioned Downing Street! We need to consider carefully the implications for psychiatry. Will we be the "left overs" after the more prestigious specialities have "opted out", and how will the essential integration of hospital and community services fare under such a novel structure? In the absence of any pilot studies no-one knows but we need to be vigilant. I spoke briefly to some of these issues at the recent BMA Secretaries' conference where we were also addressed by Sir Roy Griffiths who, however, seemed to be strangely silent concerning his report on community care!

These are matters which will need intensive debate and political lobbying over the forthcoming months and I wonder if the College needs to adopt a somewhat higher media profile to try to cope with them. Clearly these are issues where professional opinion and general political views are frequently intertwined and public statements, therefore, require careful consideration. However, it is necessary for our profession to grasp these unpleasant nettles if we are to continue to command public respect.

\section{Cefn Coed Hospital}

Philip Marshall

\section{Swansea SA2 OGH}

I appreciate Dr Marshall's remarks. The College's first task is to communicate as best as it can with all its members. That is why I have written to all members on two occasions about the White Paper and about the College's views.

I have been impressed, and so have the Government, by the unified response of the whole medical profession to Working for Patients. This has been carefully organised. Press conferences by individual 